\title{
Endodontic Management of a Mandibular Canine with Two Roots using Cone Beam Computed Tomography as a Diagnostic Aid
}

\author{
${ }^{1}$ Hina Ahmed, ${ }^{2}$ Mahendra P Singh, ${ }^{3}$ Gautam Singh
}

\begin{abstract}
Knowledge of anatomic variations is essential for endodontic success, which is related to a thorough debridement of the root canal system. About $2 \%$ of mandibular canines presented with one root and two canals, and of that, $1 \%$ had two roots and two canals. This case report presents a rare case of a mandibular canine with two roots and its endodontic management. The missed second root of mandibular canine was identified by cone beam computed tomography and was subjected to sound endodontic therapy and restored to proper function and esthetics.
\end{abstract}

Keywords: Canine morphology, Cone beam computed tomography, Mandibular canine with two roots, Post and core.

How to cite this article: Ahmed H, Singh MP, Singh G. Endodontic Management of a Mandibular Canine with Two Roots using Cone Beam Computed Tomography as a Diagnostic Aid. Int J Prosthodont Restor Dent 2016;6(4):102-105.

Source of support: Nil

Conflict of interest: None

\section{INTRODUCTION}

Proper cleaning and shaping of the root canal is of paramount importance for the success of root canal treatment. Unless the canals have been sterilized or reached a phase where microorganisms can no longer be cultivated, the prognosis is always going to be guarded. ${ }^{1}$ A proper chemomechanical preparation and a sound knowledge of the root canal anatomy and its possible anatomic variations are essential for successful treatment. Various root and root canal morphologies can be found associated with any tooth with varying degrees of incidence. Failure to appreciate the anomalous root canal anatomy in identifying a canal in such cases is one of the main reasons for failure of endodontic treatment. ${ }^{2}$ Due to knowledge

\footnotetext{
${ }^{1}$ Postgraduate Student, ${ }^{2}$ Professor and Head, ${ }^{3}$ Reader

${ }^{1-3}$ Department of Conservative Dentistry and Endodontics, People's College of Dental Sciences \& Research Centre, People's University, Bhopal, Madhya Pradesh, India
}

Corresponding Author: Hina Ahmed, Postgraduate Student Department of Conservative Dentistry and Endodontics People's College of Dental Sciences \& Research Centre People's University, Bhopal, Madhya Pradesh, India, Phone: +91-8871000790, e-mail: hinaahmed02@gmail.com of the general root canal anatomy associated with a particular tooth, many clinicians misdiagnose the tooth and its anatomy, which leads to miss the specific number of roots and/or canals, and thus, failure of the root canal treatment occurs. Mandibular canals usually present with a single root and a single canal (Vertucci Type I). The occurrence of a single root with two canals joining into a single canal apically (Vertucci Type II) and two roots in a mandibular canine is very rare, ranging from 1 to $5 \% .^{3-5}$ Although the prevalence is low, a possible variation in the number of root/root canals should be kept in mind by the clinician while carrying out the endodontic treatment for a mandibular canine. This article presents the endodontic management of a patient with varying root canal anatomy of the mandibular canine, with left canine having two separate roots, each having a single canal.

\section{CASE REPORT}

A 50-year-old female patient was referred to the Department of Conservative Dentistry and Endodontics with a fractured crown of the lower left canine (Fig. 1). The patient gave a history of pain, which was continuous and severe in intensity and aggravated upon mastication, the only relieving factor was narrowed down to over-thecounter analgesics. Patient also gave history of visiting a private dentist for endodontic therapy, which was not completed, and part of the crown was fractured during mastication. On clinical examination, it was found that the

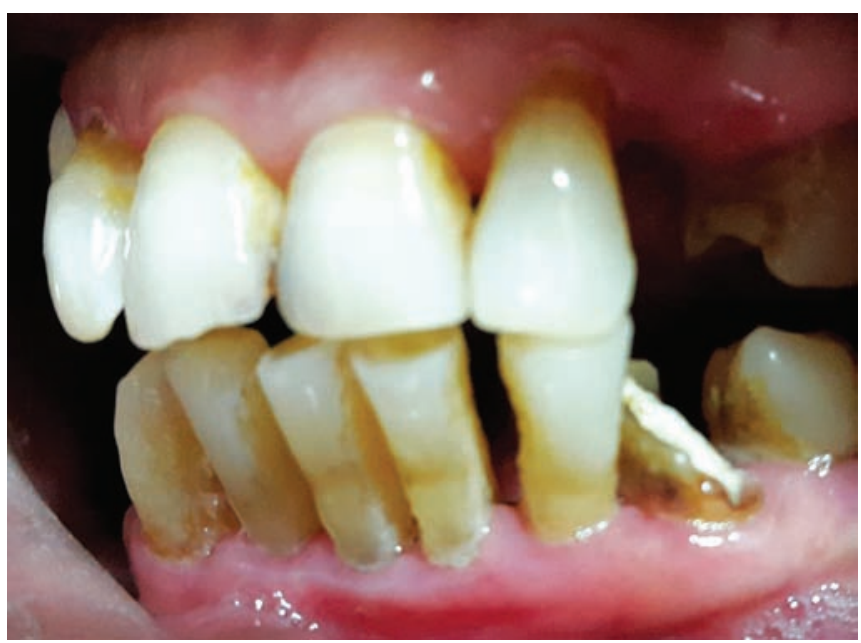

Fig. 1: Preoperative clinical picture 


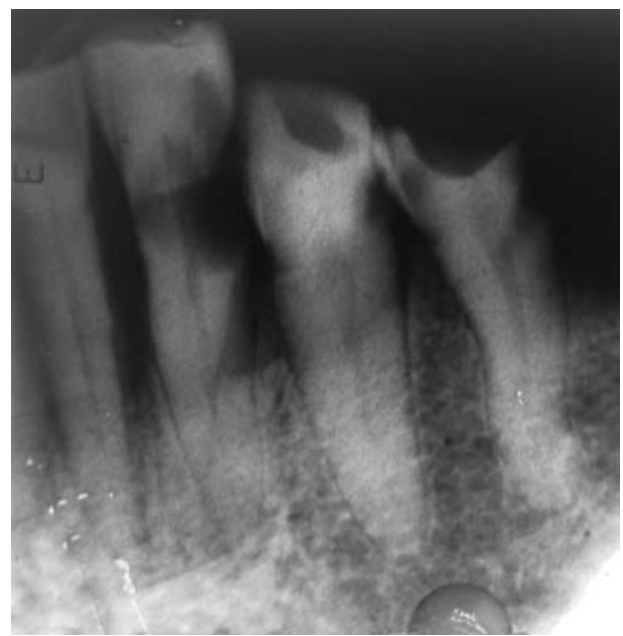

Fig. 2: Preoperative radiograph

left mandibular canine (\#33) was fractured. The patient also presented with the intraoral periapical radiograph prior to the fracture of the crown (Fig. 2). The radiograph showed evidence of a cervical radiolucency suggestive of a long-standing carious lesion involving the pulp. The periapical region shows widening of the periodontal ligament (PDL) space and radiolucency suggestive of a chronic periapical lesion. Radiograph also showed the presence of an overlapping extra canal and an additional lamina dura and PDL space. Investigation was done to confirm the missed root and canal with the help of cone beam computed tomography (CBCT) of that particular tooth. Upon CBCT analysis, it was confirmed that there was a presence of an extra root in relation to the left mandibular canine (Fig. 3). A diagnosis of apical periodontitis was made, and patient was explained about the bone loss and prognosis of that tooth. Since clinically there was no mobility with the tooth, patient was not ready for extraction, and wanted root canal to be done with the tooth, along with post, core, and crown. Consent of the patient was taken and a decision was made to do endodontic therapy of the left mandibular canine.

A modified access was done on the tooth under rubber dam isolation; the access was extended lingually to access the lingual part of the tooth to locate the missed root with the help of CBCT scans. Upon locating the canals, it was irrigated with $5.25 \%$ sodium hypochlorite to remove any debris. The canals were dried and working lengths were determined using electronic apex locater (Root Zx Mini; J Morita Co, Kyoto, Japan) and confirmed using a radiograph (Fig. 4). Both canals were prepared using crown down method using rotary files (Hero Shapers, MicroMega, Besancon, France) coated with a viscous lubricant (Glyde; Dentsply, Ballaigues, Switzerland) until a standard size 20 apical preparation with $6 \%$ taper for both canals. Copious irrigation was done with $5.25 \%$ sodium hypochlorite alternating with $17 \%$ ethylenediaminetetraacetic

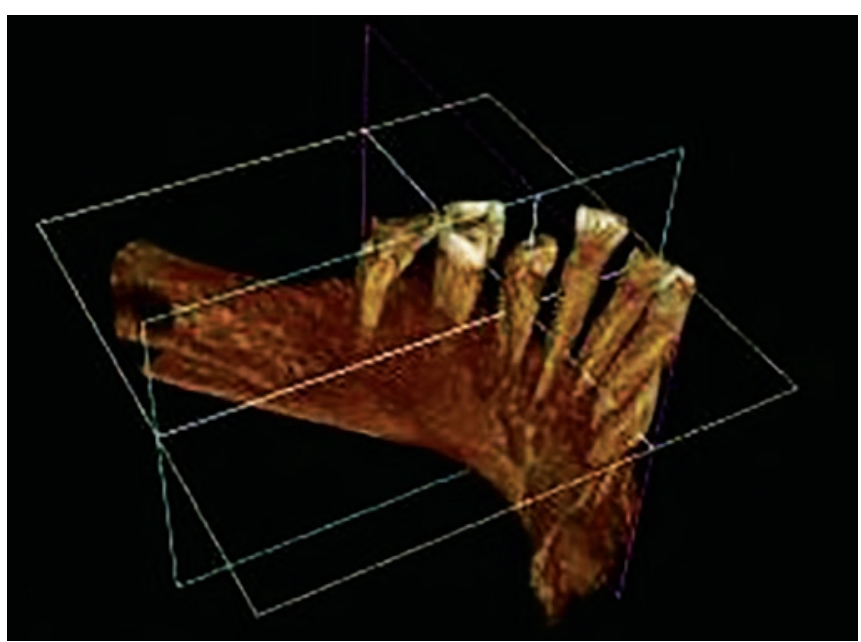

Fig. 3: The CBCT reconstruction

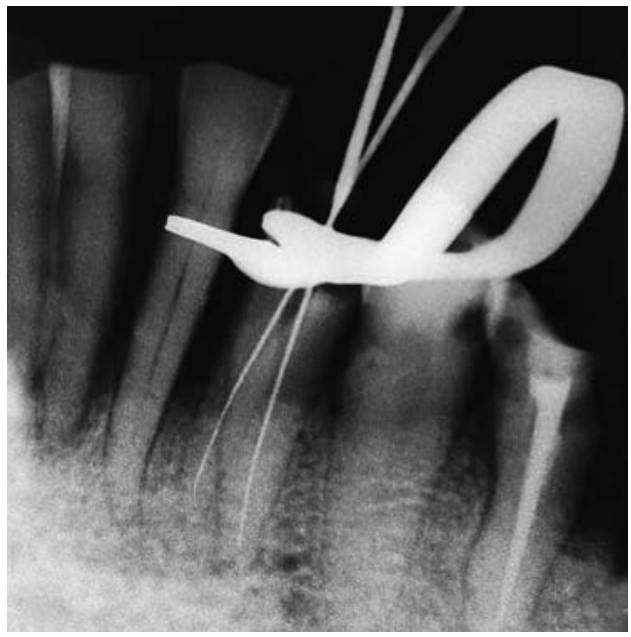

Fig. 4: Working length radiograph

acid (EDTA) solution to finish the irrigation protocol. Plain saline was used to neutralize any active irrigant followed by drying using paper points. An intracanal medication of calcium hydroxide and $2 \%$ chlorhexidine (CHX) closed dressing was used for a period of 7 days. On the subsequent visit, the patient was evaluated for any symptoms, which were found to be negative. The intracanal medicament was removed with repeated saline irrigation and ultrasonic activation (Endo Activator; Dentsply, York, PA). A 17\% EDTA solution was used to remove the smear layer. A final flush with $2 \%$ CHX was done and dried with paper points. An appropriate master gutta-percha cone was selected (Fig. 5) and compacted into the root canal with an endodontic resin sealer (AH Plus; Dentsply, Maillfer, USA). Excess gutta-percha was removed with a heat carrier and the remaining gutta-percha was vertically compacted into the root canal to ensure a three-dimensional obturation of the canal system without any voids, and a temporary coronal seal was given. In the next appointment, the temporary seal was removed and the post space 


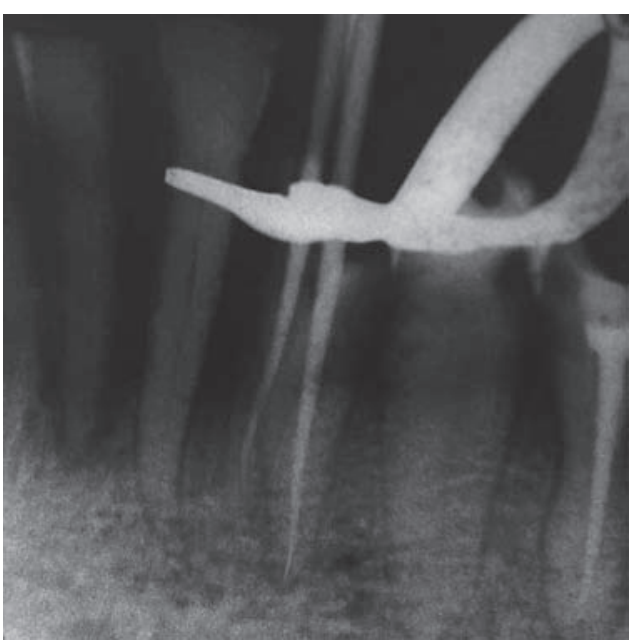

Fig. 5: Master cone radiograph

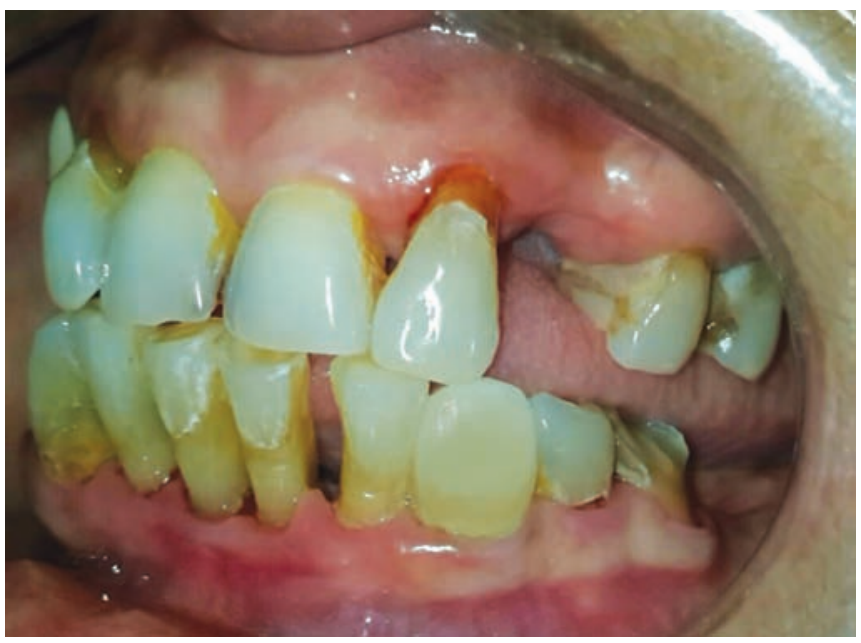

Fig. 7: Crown cementation

preparation was done using heated pluggers to remove coronal two-third gutta-percha, and with the help of pesso reamer number 4 the post space prepared and finished. A fiber-reinforced post (Easy Post; Dentsply, Ballaigues, Switzerland) was used to reinforce the tooth, luted with dual-cure resin cement (ParaCore; Coltene-Whaledent Inc., Ohio, USA) and a core was constructed over it using composite resin (Fig. 6). Crown preparation was done over the post and core, and rubber-based impression was made with retraction cord in place and a temporary acrylic crown was luted. A porcelain fused to metal crown was luted a week later to finish the treatment protocol planned for the patient (Fig. 7).

\section{DISCUSSION}

The objective of root canal treatment is to clean any remaining pulp tissue, microorganism, bacteria, and its by-products from within the root canal space prior to obturation, so as to have an environment for the healing of periapical tissues. ${ }^{2}$ Diagnosis and identification of total

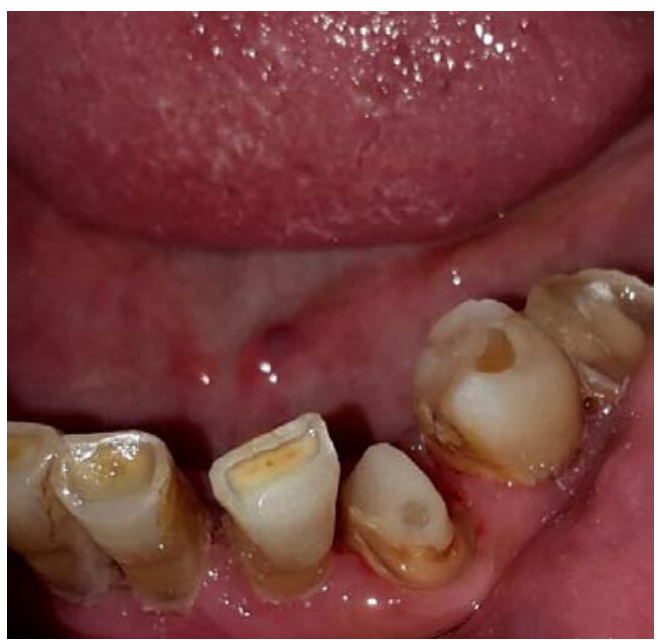

Fig. 6: Fiber post cementation

number of roots, roots canals, and any possible permutation of the root canal morphology are of utmost importance for endodontic treatment. Failure to locate and disinfect an extra root canal is one of the most common cases for the failure of root canal treatment. ${ }^{6}$

Preoperative radiograph is extremely important, as it allows for the diagnosis and identification of root and root canal anatomical variations. Though radiographs provide only two-dimensional images, radiographs taken with different horizontal angulations adequately reflect the morphological characteristics of the root and root canal system in the third dimension. ${ }^{7}$ Care should be taken during the initial radiographic examination as well as during access cavity preparation because exploration and location of the canal orifice act as a guide to navigate the canals. ${ }^{6}$ With the availability of CBCT, it is much more reliable and predictable not to miss any canal or root anomaly, ensuring that the success rate of the case is predictable.

Mandibular canines usually have a single root with one canal; however, variation in the number of roots and root canals has been reported previously. ${ }^{8-15}$ Green $^{16}$ observed two canals in a single root in 13 out of 100 teeth examined. Hess ${ }^{17}$ also observed two canals in $15 \%$ of the examined cases. Vertucci ${ }^{3}$ reported the presence of two canals in $18 \%$ of the mandibular canines. Presence of two separate roots in a mandibular canine is even rarer. Laurichesse et $\mathrm{al}^{4}$ reported that $2 \%$ of mandibular canines presented with one root and two canals, and that only $1 \%$ had two roots and two canals. Pécora et $\mathrm{al}^{18}$ studied the internal anatomy, the direction, and number of roots in mandibular canines on 830 mandibular canines, and found that only $1.2 \%$ had two canals with two orifices in a single root, and $1.7 \%$ of the examined teeth had two separate roots. Shemesh et $\mathrm{al}^{19}$ in their study found that up to $20 \%$ of mandibular canines have root canal separation and up to $6.8 \%$ are bifurcated teeth. Moreover, a 
combination of these two types of root and root canal anatomies in a single patient as present in this case has never been reported.

Root canal in a mandibular canine with a single root and single canal is quite large and usually does not cause much of technical problems during cleaning and shaping. Mandibular canines presenting with two roots or two canals are very difficult to instrument and clean. Long axis of the canal meets the crown surface at the incisal edge or on the labial surface. The emphasis should be given on the labial side of the canal; otherwise, it would lead to possible canal transportations or similar iatrogenic defects. In the present case, since there was fracture and loss of tooth structure, care was taken to remove minimum tooth structure as required for locating the canals and making straight line access and instrumentation of both the canals convenient and predictable. The complete rehabilitation of the tooth functionally and esthetically was also a concern in this case, where the patient had lost part of her functional clinical crown, a good post and core, and a full coverage crown ensured that the tooth will survive the harsh environment for years to come. It is paramount to remind at this juncture that a good diagnosis is always the key to a predictable success in endodontic therapy, and investigative procedures like CBCT are a real boon to everyday clinical practice.

\section{CONCLUSION}

The CBCT is an excellent tool for treatment planning in endodontics, and mandibular canines should be examined more carefully than done conventionally for the presence of an anatomical modification like an extra root.

\section{REFERENCES}

1. Chugal NM, Clive JM, Spãngberg LS. A prognostic model for assessment of the outcome of endodontic treatment: effect of biologic and diagnostic variables. Oral Surg Oral Med Oral Pathol Oral Radiol Endod 2001 Mar;91(3):342-352.

2. Sjögren U, Hagglund B, Sundqvist G, Wing K. Factors affecting the long-term results of endodontic treatment. J Endod 1990 Oct;16(10):498-504.
3. Vertucci FJ. Root canal anatomy of the mandibular anterior teeth. J Am Dent Assoc 1974 Aug;89(2):369-371.

4. Laurichesse, JM.; Maestroni, J.; Breillat, J. Endodontie clinique. 1st ed. Paris: Edition Cdp; 1986. p. 64-66.

5. Ouellet R. Mandibular permanent cuspids with two roots. J Can Dent Assoc 1995 Feb;61(2):159-161.

6. Haapsalo M, Udanes T, Endal U. Persistent, recurrent, and acquired infection of the root canal system post treatment. Endod Topics 2003 Nov;6(1):29-56.

7. Walton RE. Endodontic radiographic technics. Dent Radiogr Photogr 1973;46(3):51-59.

8. Heling I, Gottlieb-Dadon I, Chandler NP. Mandibular canine with two roots and three root canals. Endod Dent Traumatol 1995 Dec;11(6):301-302.

9. Holtzman L. Root canal treatment of a mandibular canine with three root canals. Case report. Int Endod J 1997 Jul;30(4): 291-293.

10. Bhardwaj A, Bhardwaj A. Mandibular canines with two roots and two canals - a case report. Int J Dent Clin 2011 JulSep;3(3):77-78.

11. Tiku AM, Kalaskar RR, Damle SG. An unusual presentation of all the mandibular anterior teeth with two root canals - a case report. J Indian Soc Pedod Prev Dent 2005 Oct-Dec;23(4): 204-206.

12. Victorino FR, Bernardes RA, Baldi JV, de Moraes IG, Bernardinelli N, Garcia RB, Bramante CM. Bilateral mandibular canines with two roots and two separate canals - case report. Braz Dent J 2009 Feb;20(1):84-86.

13. Andrei OC, Margarit R, Daguci L. Treatment of a mandibular canine abutment with two canals. Rom J Morphol Embryol 2010 Jan;51(3):565-568.

14. Gaikwad A. Endodontic treatment of mandibular canine with two root canal - a case report. Int J Dent Clin 2011 Jan;3(1): 118-119.

15. Arora V, Nikhil V, Gupta J. Mandibular canine with two root canals - an unusual case report. Int J Stomatol Res 2013;2(1):1-4.

16. Green D. Double canal in single roots. Oral Surg Oral Med Oral Pathol 1973 May;35(5):689-696.

17. Hess, W. The anatomy of the root canals of teeth of the permanent dentition. New York: Williams Wood Co; 1925.

18. Pécora JD, Sousa Neto MD, Saquy PC. Internal anatomy, direction and number of roots and size of human mandibular canines. Braz Dent J 1993 Feb;4(1):53-57.

19. Shemesh A, Levin A, Katzenell V, Itzhak JB, Avraham Z, Levinson O, Solomonov M. [Root anatomy and root canal morphology of mandibular canines in Israeli population]. Refuat Hapeh Vehashinayim (1993). 2016 Jan;33(1):19-23. 
